\title{
Temperature measurement and performance assessment of the experimental composting bioreactor
}

\author{
Jaroslav Bajko ${ }^{1, \star}$, Jan Fišer $^{1}$, and Miroslav Jícha ${ }^{1}$ \\ ${ }^{1}$ Faculty of Mechanical Engineering, Brno University of Technology, Technická 2896/2, 61669 Brno, Czech Republic
}

\begin{abstract}
Considerable amount of heat produced during composting of organic matter is usually lost to the surrounding environment. In order to utilize this potential heat source, biomass is composted in mounds or vessels and excess thermal energy is captured via heat exchangers and transported to the site for space heating, preparation of utility water and other applications. The aim of this experimental research is to measure the temperature profiles in a pilot-scale composting bioreactor and assess its performance.
\end{abstract}

\section{Introduction}

Composting is widely known as aerobic decomposition of organic materials by microorganisms, [1], producing valuable soil amendment and conditioner - compost - as well as heat, since the bio-chemical reactions presented in compost piles are mostly exothermic. The decomposition progresses slowly and steadily, thus the compost pile may be seen as a bioreactor or low grade source of combustionfree thermal energy.

Various studies have been devoted to this heat source ranging from laboratory scale experiments [2-4], to pilotscale reactors [5-8] as well as commercial scale enterprises $[9,10]$ with the aim of characterizing the amount of heat that can be captured and utilized. Recently, all systems using heat from composting processes have been united under term "Compost Heat Recovery Systems" (CHRSs), cf. [11, 12].

Subject of this paper is to present a pilot-scale composting bioreactor with the long-term within-pile temperature measurement. The CHRS based on hydronic system, cf. [5], is studied with the analysis of internal compost thermodynamics when heat is extracted from the pile. This experiment was conducted with the intent to create the simplest form of pilot-scale CHRS using buried hydronic heat exchanger and to measure the heat recovery rate of the system.

\subsection{General composting practise}

Design of CHRS include many variables that need to be taken into account for succesfull composting operation and thus the production of heat, $[1,13]$. These include external factors: climatic (weather, seasons of the year), exposure to surrounding environment (open or in-vessel

\footnotetext{
^e-mail: bajko@fme.vutbr.cz
}

facility), insulation, duration of composting as well as internal factors: energy and nutrient content of the composting material, its degradability, porosity. All of these factors create conditions for microbial activity that is responsible for the composting process as a whole.

Considering evidence based on [14, 15], basic measurable variables (and their optimal range) involved in composting read as follows:

- Carbon-to-Nitrogen $(\mathrm{C}: \mathrm{N})$ ratio of the whole mix around $30: 1$,

- Moisture between $50-60 \%$,

- Oxygen content between $10-18 \%$ (active phase) and $1-5 \%$ (maturation phase),

- Temperature under $65^{\circ} \mathrm{C}\left(150^{\circ} \mathrm{F}\right)$,

- Porosity, i.e. free air space $35-50 \%$,

- $\mathrm{pH}$ between $5.5-8.0$.

Composted organic material should be thoroughly mixed, should not contain particles larger than $8 \mathrm{~cm}$ and toxic substances. Moreover, drainage should be included and compost leachate reused in order to avoid the development of anaerobic conditions, cf. [16].

\subsection{Thermodynamic model of compost piles}

Thermal balance of a composting system, cf. [17-19], can be written as the heat accumulation term equals to the input $Q_{\text {in }}$, output $Q_{\text {out }}$ and transformation $Q_{\text {tran }}$ energy terms as follows:

$$
\frac{\mathrm{d}(m c T)}{\mathrm{d} t}=Q_{\mathrm{in}}-Q_{\mathrm{out}}+Q_{\mathrm{tran}},
$$

where the left-hand side refers to sensible heat of the composting mass, input term includes heat gain due to solar radiation and enthalpy of incoming air. Output term consists of heat losses through system boundaries (including 
conductive, convective and radiative losses), enthalpy of exiting gas and heat taken away via heat recovery system. Finally, the transformation term refers to bio-chemical reactions occuring during composting process that can be both exo- or endo-thermic.

Among the terms involved in the heat balance (1), the most significant contributors are the biologically generated heat and enthalpy of exit water vapour, cf. [11, 18].

\section{Materials and Methods}

\subsection{Experimental composting bioreactor}

The composting bioreactor was initially designed as a standalone cylindrical pile with diameter of $3 \mathrm{~m}$ and height of $2 \mathrm{~m}$. Volume of this composting reactor is 14.137 $\mathrm{m}^{3}$ resulting in the surface area-to-volume ratio 1,83 : $1\left[\mathrm{~m}^{2} / \mathrm{m}^{3}\right]$, assuming the pile stands on the ground in direct contact with soil, i.e. base contact area is excluded.

Compost feedstock consists of the following mixture of materials:

- Wood chips - softwood, $3140 \mathrm{~kg}$,

- Horse manure - fresh, $2403 \mathrm{~kg}$,

- Vegetable wastes and leaves, $260 \mathrm{~kg}$,

where the moisture content of wood chips, wet weight of all materials were obtained by measurement. Other material properties were taken as average values from [1]. Resulting moisture of the initial compost recipe is estimated to $M_{\text {mix }}=47,5 \%$.

Estimation of the Carbon-to-Nitrogen ratio of the whole mixture then follows from

$$
(\mathrm{C}: \mathrm{N})_{\operatorname{mix}}=\frac{\sum_{i=1}^{n} C_{i} W_{i}\left(1-M_{i}\right)}{\sum_{i=1}^{n} N_{i} W_{i}\left(1-M_{i}\right)}=113,2: 1,
$$

where $C_{i}$ is the carbon content, $N_{i}$ is the nitrogen content (dry weight), $W_{i}$ is the wet weight and $M_{i}$ is moisture content of the $i$-th material. Note, that wood chips as carbon-rich material were used intentionally in abundance (accordingly to J. Pain method, $[5,8]$ ) in order to prolong the thermophilic phase due to higher $\mathrm{C}: \mathrm{N}$ ratio.

Fig. 1 shows the reactor design with dimensions and initial position of the within-pile hydronic heat exchanger as well as polypropylene (PP) pipes containing thermal sensors.

\subsection{Within-pile temperature measurement}

Conditions created inside the composting reactor represent a challenge for long-term continual measurements. These involve high humidity, $\mathrm{pH}$ variations, presence of chemical reactions and microorganisms that could adversely affect any part of the measuring electronics. For this reason, simple replacement and access to each part of the system was a crucial condition when designing the experimental measurement.

Therefore, for continuous within-pile temperature measurement, we have designed a simple, inexpensive solution consisting of $2.1 \mathrm{~m}$ long PP pipe and a wooden rod

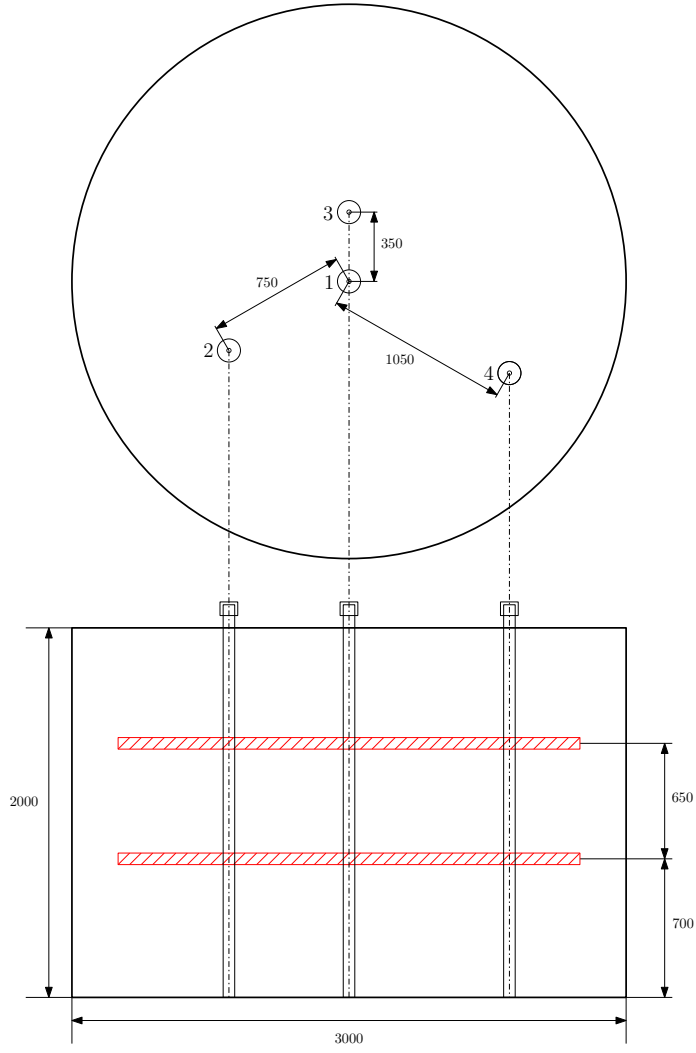

Fig. 1: Composting bioreactor shape, dimensions and positions of PP pipes containing thermal sensors. Location of the hydronic heat exchanger coils.

that can be inserted inside the pipe and pulled up again. At the beginning of the reactor construction, 4 PP pipes were installed, i.e. a central pipe and another three pipes were placed radially in $120^{\circ}$ angle with distance 350,750 and $1050 \mathrm{~mm}$ from the center in accordance with Fig. 1. This configuration of sensors was chosen with the assumtion of radial symmetry of temperature distribution, i.e. that the organic matter is evenly distributed in each horizontal layer of the bioreactor.

Into each PP pipe was inserted a wooden rod (Fig. 2) equiped with 2 measuring sections, each containing a thermal digital thermometer (DS18S20, accuracy $\pm 0.5^{\circ} \mathrm{C}$ from $-10^{\circ} \mathrm{C}$ to $+85^{\circ} \mathrm{C}$ ). The wooden rod was used in order to minimize vertical conductive heat transfer that could affect neighbouring thermal sensor. Moreover, convection inside the pipe was eliminated via polyuretane (PU) foam plugs.

For faster registration of temperature variatons the thermometers were tightly attached to the aluminium plates (Fig. 3) due to their high thermal conductivity and direct contact with the internal pipe surface. Data from within-pile and ambient sensors were collected by 1-wire line (Bus A) and processed with PLC device.

\subsection{The heating system}

Fig. 1 depicts also the position of two horizontal layers of the heat exchanger which were built in the composting matter 700 and $1350 \mathrm{~mm}$ above the ground (initially at the 


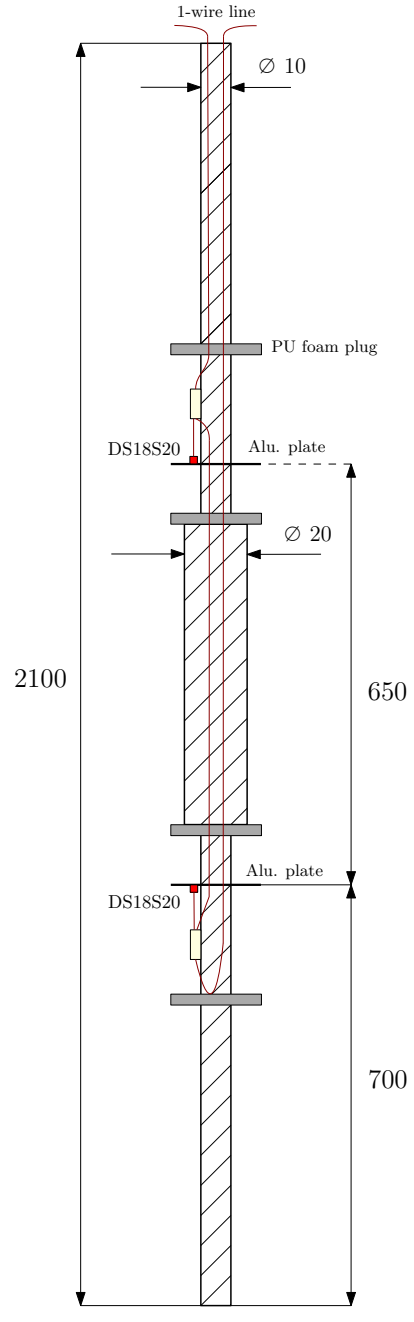

Fig. 2: Internal wooden rod (inserted into the PP pipe) with two separated measuring sections.

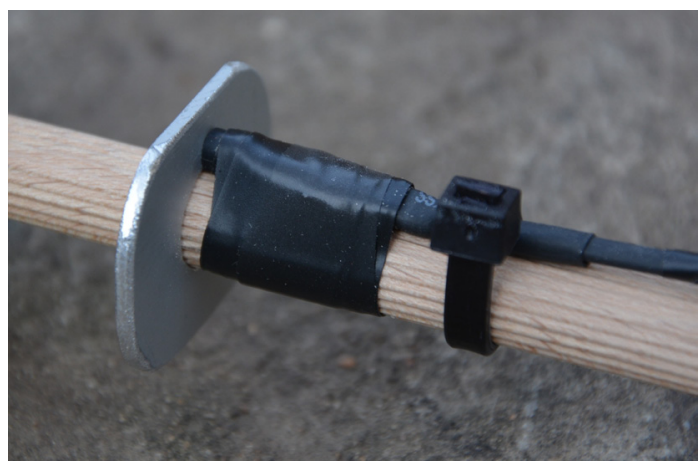

Fig. 3: Detail of the thermometer DS18S20 attached to the aluminium plate.

same height as the thermometers in the PP pipes). Each layer of the heat exchanger formed a spiral (as shown in Fig. 4 and 5) from low density polyethylene (LDPE) pipe (diameter $25 \mathrm{~mm}$, wall thickness $3.5 \mathrm{~mm}$ ) of length 26.5 $\mathrm{m}$, which was attached to the concrete wire mesh for the sake of its from stability. The overall heat exchange sur- face of the within-pile heat exchanger was therefore 4.16 $\mathrm{m}^{2}$.

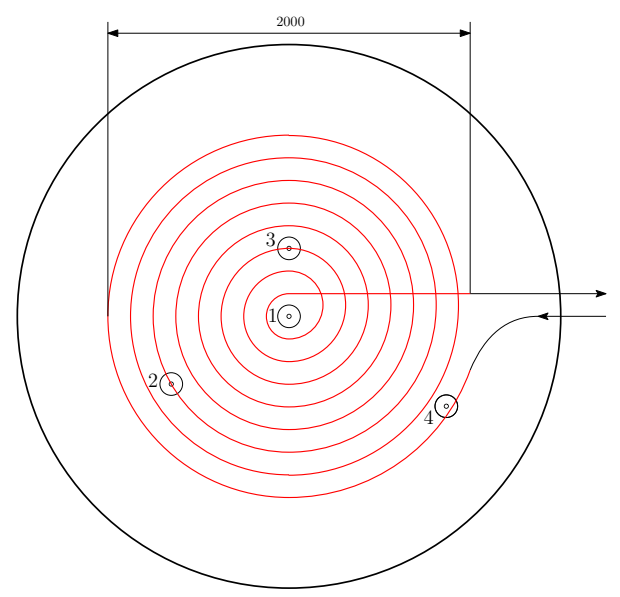

Fig. 4: A layer of the spiral heat exchanger, directions of fluid flow and positions of PP pipes with thermometers.

Both layers of the within-pile heat exchanger were connected with $12 \mathrm{~m}$ long insulated line to the radiator (heat sink), expansion vessel, air release valve and the flow meter allowing the measurement of the volumetric flow rate. The working fluid (water) circulated in a closed-loop circuit by electically powered circulating pump (UPS 25$60)$ with adjustable input power.

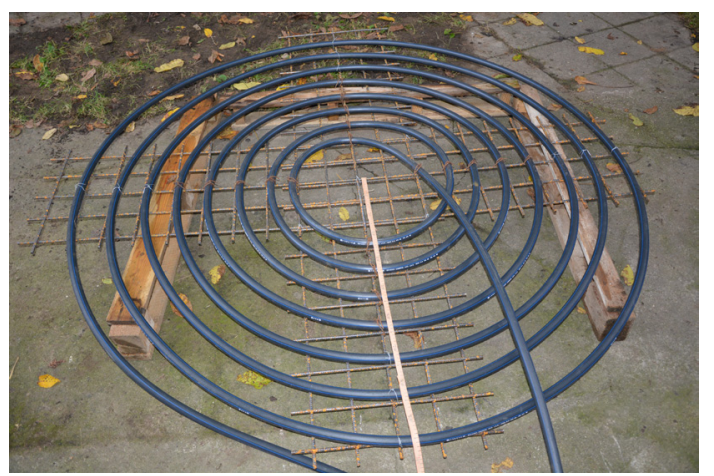

Fig. 5: A part of the heat exchanger made of LDPE pipe $(25 \times$ $3.5 \mathrm{~mm}$ ) attached to the concrete wire mesh.

Second 1-wire line (Bus B) comprised of sensors measuring approximate temperature of water inside the heating system. Thermometers attached to the brass fittings (Fig. 6) provided estimation of water temperature entering and leaving the bioreactor allowing us to compute direct heat recovery rate. Insulation by PE foam was tightly wrapped around the fitting.

\section{Results}

Experimental raw data were collected in a period of $5 \mathrm{~s}$ from each thermometer starting on Nov 5. at 16:14. For graphical output the data were averaged for each minute. Graph in Fig. 7 shows first 9 days of within-pile temperature measurements. 


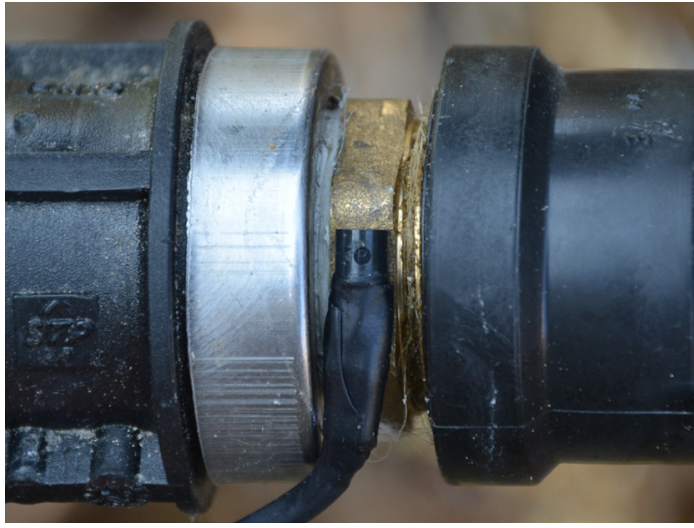

Fig. 6: Thermometer attached to the brass fitting.

Central pole P1 (sensors 3C and F8, cf. legend of Fig. 7 and 8) measures core temperature of the mound, which represents the overall composting dynamics. Self-heating of the pile is well documented as the core temperature raises exponentially up to $78{ }^{\circ} \mathrm{C}$ followed by similar pattern for both layers in poles P2 (sensors $6 \mathrm{C}$ and $3 \mathrm{~F}$ ) and P3 (sensors FD and EF).

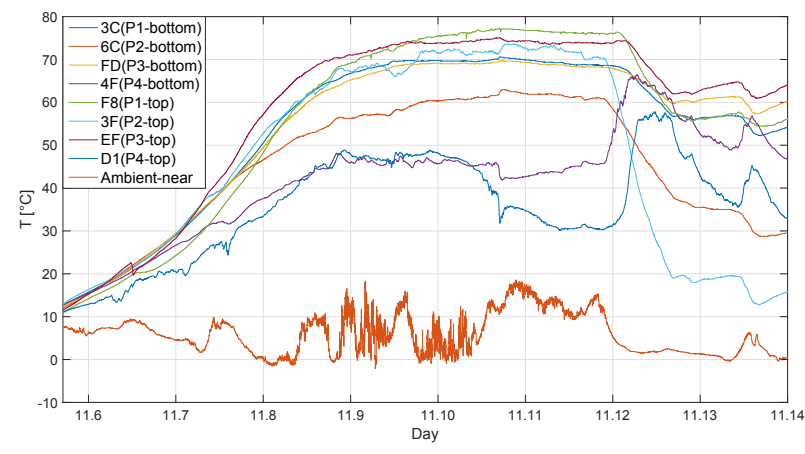

Fig. 7: Temperature profiles at 8 points (bottom layer 700 $\mathrm{mm}$ and top layer $1350 \mathrm{~mm}$ above the ground) within the bioreactor and ambient (Nov 5. to Nov 14.). P1 - center, P2 - $750 \mathrm{~mm}, \mathrm{P} 3$ - $350 \mathrm{~mm}, \mathrm{P} 4$ - $1050 \mathrm{~mm}$ from the center.

Measurement in pole P4 (sensors 4F and D1) shows slower temperature growth due to their shortest radial distance $(0.45 \mathrm{~m})$ from the surface. Note, the average ambient temperature during this early period was $5.9{ }^{\circ} \mathrm{C}$.

After rapid temperature growth into the thermophilic stage and exceeding the optimal range of $45-65{ }^{\circ} \mathrm{C}$, sudden fall accompanied with lower ambient temperatures was observed on Nov 11. This behaviour is well known from practise, when microorganisms start to perish due to the excess heat they produce.

Although the temperature drop occured, a stable thermophilic phase has recovered and lasted in average in the range $45-65{ }^{\circ} \mathrm{C}$ till Dec 1 . (27 days, the end of this period is shown in Fig. 8.) For the computation of the power output of the bioreactor, the goal is to find an amount of heat that could be recovered without adversely affecting the composting process. To reach this goal, we first run the heating circuit for 15, 30 and 45 minutes on Nov 25, 26 and 27 , respectively, with the volumetric flow rate $\dot{V}=4.6$ $1 / \mathrm{min}=7 . \overline{66} \times 10^{-5} \mathrm{~m}^{3} / \mathrm{s}$.

All three runs and heating system dynamics (transient and stable state) are depicted in Fig. 8. Among 8 withinpile sensors, another two are showing temperature profiles of water entering (1A - Compost in) and leaving (1ACD Compost out) the pile.

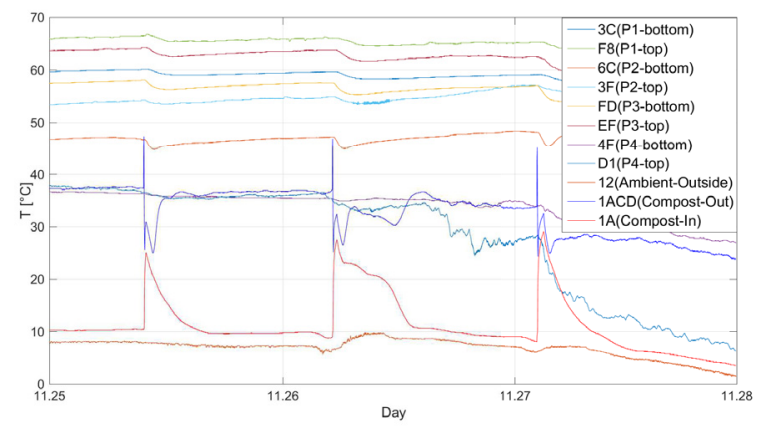

Fig. 8: Within-pile temperature profiles, ambient and temperature of water circulating at points Compost In/Out in the heating circuit (Nov 25. to Nov 28.).

From stable states for each run, we obtained the following average temperature difference $\Delta T=6.01 ; 4.88$ and $4.33{ }^{\circ} \mathrm{C}$ between water entering and leaving the bioreactor. The average power output for each run than follows from

$$
P=\dot{m} c_{p} \Delta T, \quad[\mathrm{~W}]
$$

where $\dot{m}=\rho \dot{V}[\mathrm{~kg} / \mathrm{s}]$ is the mass flow rate and $c_{p}$ is the heat capacity at constant pressure. Taking properties of water at $30{ }^{\circ} \mathrm{C}\left(\rho=995.6 \mathrm{~kg} / \mathrm{m}^{3}\right.$ and $\left.c_{p}=4176 \mathrm{~J} / \mathrm{kg} . \mathrm{K}\right)$ we get thermal power output of the bioreactor $P=1914 ; 1554$ and $1379 \mathrm{~W}$ for each run, respectively.

\section{Discussion}

The pilot-scale standalone composting reactor performed well in early days as shown in Fig. 7, i.e. it reached thermophilic stage in three days after construction and even exceeded optimal range which led to sharp fall in average temperature within 24 hours. However, stable thermophilic period has established for almost a month and after that it remained in lower mesophilic range $15-44$ ${ }^{\circ} \mathrm{C}$ for the whole winter even if the temperatures dropped deeply bellow zero. Average within-pile temperatures have been continuously recovering during spring reaching middle and higher mesophilic range in summer.

Fig. 7 also shows how within-pile temperatures change over the distance from the pile center, especially lower average temperatures measured in pole $\mathrm{P} 4$ indicate the rate of thermal loses through mound boundaries. In order to reduce heat loses and improve the whole performance of the composting reactor, it was confirmed that the insulation plays a crucial role. Simple layer of straw or hay covering the surface would satisfy insulation need as well as aeration from sides, cf. [8]. 
The heat exchanger built from two spirals of LDPE pipe (total heat exchange suraface of $4.16 \mathrm{~m}^{2}$ ) proved to be well designed for the reactor with volume $14 \mathrm{~m}^{3}$. The whole circuit also worked good without any significant problems transfering enough heat from the pile.

Graph in Fig. 8 clearly shows, how each run of the heating circuit led to visible temperature drop at all withinpile sensors. Moreover, regeneration of temperatures as well as the slight descending tendency of the average reactor temperature can be observed. This behaviour suggests that achieved heat recovery rate was too high in each run, thus the long-term performance of the bioreactor at these power outputs is questionable. Therefore, real long-term overall performance is limited by $1379 \mathrm{~W}$ from top for this pilot-scale bioreactor.

Comparing results published in [11], where lab-scale reactors reached heat recovery rate $1895 \mathrm{~kJ} / \mathrm{h}=0.526$ $\mathrm{kW}$ and pilot-scale reactors reached $20035 \mathrm{~kJ} / \mathrm{h}=5.565$ $\mathrm{kW}$, our composting system with top output of $4964 \mathrm{~kJ} / \mathrm{h}$ $=1.379 \mathrm{~kW}$ belongs to weakly performing pilot-scale experimental bioreactors.

\section{Acknowledgement}

Authors greatly acknowledge support from the Project Fond vědy 2017 (No. RV90700003).

\section{References}

1. R. Rynk, M. van de Kamp, G. Willson, M. Singley, T. Richard, J. Kolega, F. Couin, L. Laliberty, D. Kay, D. Murphy et al., On-Farm Composting Handbook (Ithaca, NY: Northeast Regional Agricultural Engineering Service (NRAES-54), 1992)

2. D. Chambers, Master's thesis, Galway-Mayo Institute of Technology (2009)

3. R.A. Gnanaraj, Asian Journal of Scientific Research 5, 185 (2012)
4. H. Seki, S. Kiyose, S. Sakida, Journal of Agricultural Meteorology 70, 1 (2014)

5. I. Pain, J. Pain, The methods of Jean Pain: Another kind of garden (Draguignan: Ancienne Imprimerie NEGRO, 1972)

6. Z. Adams, Master's thesis, University of Vermont, Burlington (2005)

7. C. Gilson, Master's thesis, University of Waterloo (2009)

8. G. Brown, The compost-powered water heater (Woodstock: The Countryman Press, 2014)

9. F. Di Maria, M. Benavoli, M. Zoppitelli, Waste Management 28, 805 (2008)

10. G. Irvine, E.R. Lamont, B. Antizar-Ladislao, International Journal of Chemical Engineering 2010, 10 (2010)

11. M.M. Smith, J.D. Aber, R. Rynk, Compost Science \& Utilization (2016)

12. R.F. Zhao, W. Gao, H. Guo, Int J Agric \& Biol Eng 10, 1 (2017)

13. R.T. Haug, The Practical Handbook of Compost Engineering (CRC Press, 1993)

14. E. Epstein, Industrial composting: Environmental engineering and facilities management (CRC Press, 2011)

15. A. Chiumenti, R. Chiumenti, L. Diaz, G. Savage, L. Eggerth, N. Goldstein, Modern composting technologies (Emmaus, PA: JG Press, 2005)

16. M.M. Smith, J.D. Aber, Tech. rep., Durham, NH: University of New Hampshire Cooperative Extension (2017), 64p

17. E.G. Khater, A.H. Bahnasawy, S.A. Ali, Journal of Environmental \& Analytical Toxicology 4 (2014)

18. I.G. Mason, Waste Management 26, 3 (2006)

19. I.G. Mason, Ph.D. thesis, University of Canterbury (2007) 